\title{
Patient Characteristics Associated with Medication Adherence
}

\author{
Sharon J. Rolnick, PhD, MPH; Pamala A. Pawloski, PharmD; Brita D. Hedblom, BS; \\ Stephen E. Asche, MA; and Richard J. Bruzek, PharmD
}

\begin{abstract}
Objective: Despite evidence indicating therapeutic benefit for adhering to a prescribed regimen, many patients do not take their medications as prescribed. Non-adherence often leads to morbidity and to higher health care costs. The objective of the study was to assess patient characteristics associated with medication adherence across eight diseases.

Design: Retrospective data from a repository within an integrated health system was used to identify patients $\geq 18$ years of age with ICD-9-CM codes for primary or secondary diagnoses for any of eight conditions (depression, hypertension, hyperlipidemia, diabetes, asthma or chronic obstructive pulmonary disease, multiple sclerosis, cancer, or osteoporosis). Electronic pharmacy data was then obtained for 128 medications used for treatment.
\end{abstract}

Methods: Medication possession ratios (MPR) were calculated for those with one condition and one drug $(n=15,334)$ and then for the total population having any of the eight diseases $(n=3 \mid, 636)$. The proportion of patients adherent (MPR $\geq 80 \%$ ) was summarized by patient and living-area (census) characteristics. Bivariate associations between drug adherence and patient characteristics (age, sex, race, education, and comorbidity) were tested using contingency tables and chi-square tests. Logistic regression analysis examined predictors of adherence from patient and living area characteristics.

Results: Medication adherence for those with one condition was higher in males, Caucasians, older patients, and those living in areas with higher education rates and higher income. In the total population, adherence increased with lower comorbidity and increased number of medications. Substantial variation in adherence was found by condition with the lowest adherence for diabetes (5I\%) and asthma (33\%).

Conclusions: The expectation of high adherence due to a covered pharmacy benefit, and to enhanced medication access did not hold. Differences in medication adherence were found across condition and by patient characteristics. Great room for improvement remains, specifically for diabetes and asthma.

Keywords: Medication Adherence; Patient Compliance; Pharmacy Benefits

Corresponding Author: Sharon J. Rolnick, PhD, MPH; HealthPartners Research Foundation; 8170 33rd Ave. S.; MS 2111 IR; Bloomington, MN 55425; Tel: 952-967-5016; Fax: 952-967-5022; Email: Cheri.J.Rolnick@ healthpartners.com and cheri747@gmail.com
Received: July 25, 2012

Revised: November 16, 2012

Accepted: January 9, 2013

Published online ahead of print: April II, 2013

doi: $10.3121 / \mathrm{cmr} .2013 .1113$

Grant support: This study was funded by Novartis Pharmaceuticals Corporation, East Hanover, NJ. The proposal was developed and conducted by HealthPartners Research Foundation. There are no conflicts of interest for any of the authors, nor have there been in the past. 
T

he lack of adherence to prescribed medication is an important health challenge. Despite evidence indicating the therapeutic benefit for adhering to a prescribed regimen, many patients do not take medications as prescribed. Several studies have been conducted examining medication adherence for various conditions, and adherence has consistently been found to be suboptimal. ${ }^{1-7}$ Failure to take medication as prescribed increases the risk that patients will not get the intended benefit, often leading to negative sequelae., ${ }^{3,8-12}$ Further, not adhering to one's prescribed medications is likely to result in higher healthcare costs overall. ${ }^{10}$ Thus, understanding factors associated with maintaining one's medication regimen is important to patients, providers, and health plans.

External factors such as cost and access to the needed medication play a role in non-adherence. However, within our integrated health care system, where most patients have access to care, a covered pharmacy benefit, and easy access to pharmacies, one might expect a lower rate of non-adherence than in the general population. Pharmacies are available in all clinics owned by the medical group. In addition, phone-in, mail order, and internet prescription refill options allow patients the ability to order medications 24 hours a day. Nevertheless, the health system has identified non-adherence as a major area of concern.

While the literature has reported some evidence of variation of adherence by age, race, co-morbidity status, and socioeconomic status (SES) (higher adherence in those older, white, lower co-morbidity, and higher SES), ${ }^{8,9,13-17}$ the majority of studies conducted have examined adherence within a given disease state. Few have examined adherence across multiple conditions to determine whether associations between adherence and patient characteristics are consistent. Such information could be helpful in health systems such as ours to develop focused interventions. Therefore, to increase the understanding of medication adherence in our population, we examined adherence across multiple health conditions, examining associated patient and drug-related characteristics. The purpose of this paper is to report on the patient characteristics associated with adherence within this large integrated health system.

\section{Methods}

\section{Study Sample}

This study was conducted within a large, Midwestern, integrated health system serving over 750,000 patients. The study sample was comprised of all patients age 18 and over with at least one of eight medical conditions that included asthma/chronic obstructive pulmonary disease (COPD), cancer, depression, diabetes, hypercholesterolemia, hypertension, multiple sclerosis (MS), or osteoporosis. The conditions selected represented the most prevalent conditions treated. It also included conditions with both low cost and high cost medication and conditions where most care is delivered through primary care, as well as conditions treated primarily through specialty care. To be eligible, patients were required to have a 12-month (allowing for an additional 15 days) record of prescription coverage and a minimum of two prescription fills for the medication used to treat one of the above-mentioned conditions.

Patients within the health system have a pharmacy benefit that is included in their health coverage. While medications are readily available at in-clinic pharmacies and through the health plan-owned mail order pharmacy, patients can fill prescriptions at local pharmacies. The data associated with these fills is captured in the health system's claims database and approximately one-third of our patients choose to use local pharmacies.

\section{Data Source}

Patient adherence for each medication was tracked for one year ( +15 days) using the most current information available during the study period of $1 / 1 / 2007$ to $3 / 31 / 2009$. Data on diagnoses for a given individual was linked to medication associated with that diagnosis using both the electronic medical record (EMR) and the pharmacy administrative database to ensure that prescriptions corresponded to the condition. The diagnosis had to occur within 24 months prior to the associated prescription order. A minimum of two prescription fills of at least a 28-day supply were required to enable us to calculate adherence and to eliminate any medications that may have been intended for an acute situation. We recognized that those who stop medication after a one-time use would be excluded but wanted to focus on adherence patterns in patients attempting to take a medication chronically.

International Classification of Diseases, Ninth Revision Clinical Modification (ICD-9-CM) codes were used to identify patient encounters with a primary or secondary diagnosis for any of the eight diseases of interest. The health plan's data repository includes medical encounters and pharmacy utilization data stored in a relational database that is updated monthly. Prescription order data was obtained using generic product identifier (GPI) codes (Master Drug Database v2.0, Medi-Span, Indianapolis, IN) for 128 medications used to treat the conditions enumerated (Appendix A). Clinical data points (gender, age, country of origin, language, race) were extracted electronically from the EMR reporting system (Epic Systems Corporation, EpicCare Ambulatory EMR, Madison, WI). Drug records were examined for each drug to create a final data set for adherence calculations.

\section{Calculation of Medication Adherence}

To calculate adherence, we utilized the Medication Possession Ratio (MPR) and a cut-point of $80 \%$, a commonly used calculation in health research and supported by the International Society for Pharmaceutical and Outcomes Research. ${ }^{10,18-24}$ Adherence was calculated for each medication 
a patient was taking. The days' supply for the last refill was not included in the adherence calculation. The number of days of study participation was determined by subtracting the first fill date from the last fill date within a 12-month (+15 day) period..$^{18}$

Once we had computed a continuous measure of MPR, we computed a binary indicator of adherence. For this binary measure we required an MPR $\geq 0.80$ (a cut point of $80 \%$ or above required for a patient to be considered adherent). If the MPR was $<0.80$, the patient was considered non-adherent. Medication adherence was calculated individually for each patient for each medication and for each disease. Patients on more than one medication for a single disease were evaluated for each individual medication and deemed non-adherent to their regimen if they did not achieve the $80 \%$ level for any prescribed medications.

\section{Data Sources and Variables}

Age (categorized by decade) and race were obtained for all study subjects from clinical records located within the EMR. Co-morbidity was measured by a count of Charlson $(0,1,2$, $3+$ ) co-morbid conditions using two primary or secondary diagnosis codes located within the EMR within the study period. This count of Charlson conditions considers many conditions beyond the eight conditions under study. Because patient-level measures of SES were not available, we used proxy measures. ${ }^{25}$ Each patient's address at the date of first prescription fill (or most recent address) was geo-coded and linked to block, tract, or zip-code level 2000 U.S. census data. Patient living area variables from the census that were used as proxies for patient SES included percentage of adults $25+$ with a high school education, percentage of individuals living in poverty, and median family income. These census variables were summarized in quartiles.

\section{Analysis}

To illustrate the distribution of MPR values within each condition, MPRs were plotted for patients having one condition and on one drug. The proportion of patients adherent (MPR $\geq 80 \%$ ) to their medications was summarized by patient and living-area (census) characteristics. Bivariate associations between drug adherence and patient and livingarea characteristics were examined and tested using contingency tables and chi-square tests to allow for the possibility of nonlinear patterns in multi-category variables. These summaries were computed using the population of patients who had only one of the eight conditions who also received only one medication for their single condition $(n=15,334)$. This enabled examination of data with the least confounded population. The analyses were then repeated on the total population of patients (those with any number of the eight conditions under study), and any number of medications for those conditions $(n=31,636)$. The data from this larger group of patients was also used in unconditional logistic regression analysis to examine predictors of adherence from the set of patient and living area characteristics.
We examined data for patients with diabetes both including and excluding those who take insulin-only for treatment. For purposes of this paper, we included all diabetes patients. For asthma patients we included those on chronic medications, as we could not track medications used only "as needed".

Separate regression equations were computed by condition. Variables included in each regression equation included gender, race, age group, proportion of adults in living area with a high school education, median income of families in the living area, count of Charlson conditions, and number of prescribed drugs. The proportion of residents living in poverty and number of conditions were not included in these models due to their conceptual and empirical overlap with other variables. The sample size for each model is restricted to those who have the full set of non-missing covariates. Statistical significance is tested at the alpha $=0.05$ level and there was no adjustment for multiple tests. Institutional Review Board (IRB) approval was granted for the conduct of this study.

\section{Results}

\section{Patient Demographics}

Table 1 presents characteristics of both underlying patient populations (single condition and total population). Patients were predominantly female $(60.8 \%)$, white $(82 \%)$, and nearly half were from 50 to 69 years of age. Co-morbidities were relatively similar in both groups $(77 \%$ single condition and $65 \%$ total population) with a Charlson comborbidity count of 0 . In the total population $(n=31,636), 65 \%$ had only one of the eight conditions, and $49 \%$ were on one drug. Of the eight conditions studied, the three conditions affecting the most people were hypertension, depression, and hyperlipidemia.

\section{Adherence by Condition}

Within the 15,334 patient group, substantial variation in MPR was found by condition. Hypertension, hyperlipidemia, osteoporosis, MS, and cancer had greater than $75 \%$ of patients considered adherent. Adherence rates for depression (62\%), diabetes (51\%), and asthma/COPD (33\%) fell well below the $80 \%$ MPR threshold. This variation by condition was true for the total population as well, ranging from $32 \%$ to $75 \%$. Figure 1 presents the distribution of MPR values for patients having one condition on one drug. The center of each circle on the bubble plot provides the MPR value. The area of each circle is proportional to the number of patients with each integer MPR value, and therefore, the extent of the circle does not signify MPR values $>1$. The conditions are ordered left-toright by descending median MPR.

\section{Adherence by Patient Characteristics}

After examining adherence by condition, we then examined patterns of overall drug adherence by patient characteristics within each specific condition. We did this for those with a single condition and then for those with multiple conditions. As findings for both groups were similar, we are presenting results for the total population (table 2). 
Table 1. Sample characteristics for those patients with a single condition and one medication, and for the total population.

\section{Patients with One Condition $(\mathrm{N}=15334)$ \\ n (\%)}

Female

Race/ethnicity

White

Black

Asian

Hispanic

American Indian

Other

No answer

Age (years)

18-29

30-39

40-49

50-59

60-69

70-79

80-89

$90+$

Charlson Comorbid Condition Count

0

1

2

$3+$

Condition (sum >100\%)

Hypertension

Depression

Hyperlipidemia

Asthma/COPD

Diabetes

Osteoporosis

Cancer

Multiple Sclerosis

Number of conditions

1

2

3

4

5

6

Number of drugs

1

2

3

4

$5+$

$9319(60.8)$

12673( 82.7)

867 (5.7)

421 (2.8)

252 (1.6)

$89(0.6)$

$104(0.7)$

928 (6.1)

$823(5.4)$

1370 (8.9)

2457 (16.0)

3998 (26.1)

$3172(20.7)$

1858 (12.1)

$1412(9.2)$

244 (1.6)

11869 (77.4)

2337 (15.2)

823 (5.4)

305 (2.0)

5505 (35.9)

4349 (28.4)

2744 (17.9)

$1012(6.6)$

$842(5.5)$

551 (3.6)

250 (1.6)

$81(0.5)$

15334 (100.0)

0

0

0

0

0

15334 (100.0)

0

0

0

\section{Total Patients \\ $(\mathrm{N}=31636)$ \\ n (\%)}

$18955(59.9)$

26321 (83.2)

1895 (6.0)

$886(2.8)$

484 (1.5)

$230(0.7)$

$230(0.7)$

$1590(5.0)$

994 (3.1)

$1765(5.6)$

3814 (12.1)

7370 (23.3)

7071 (22.4)

5541 (17.5)

4385 (13.9)

$696(2.2)$

20570 (65.0)

7023 (22.2)

$2722(8.6)$

1321 (4.2)

18289 (57.8)

8067 (25.5)

9986 (31.6)

2672 (8.4)

4361 (14.6)

1756 (5.6)

1106 (3.5)

$117(0.4)$

20390 (64.5)

$8075(25.5)$

$2658(8.4)$

463 (1.5)

$42(0.1)$

$8(0.03)$

15429 (48.8)

$7946(25.1)$

4249 (13.4)

$2228(7.0)$

1784 (5.6)

COPD, chronic obstructive pulmonary disease 


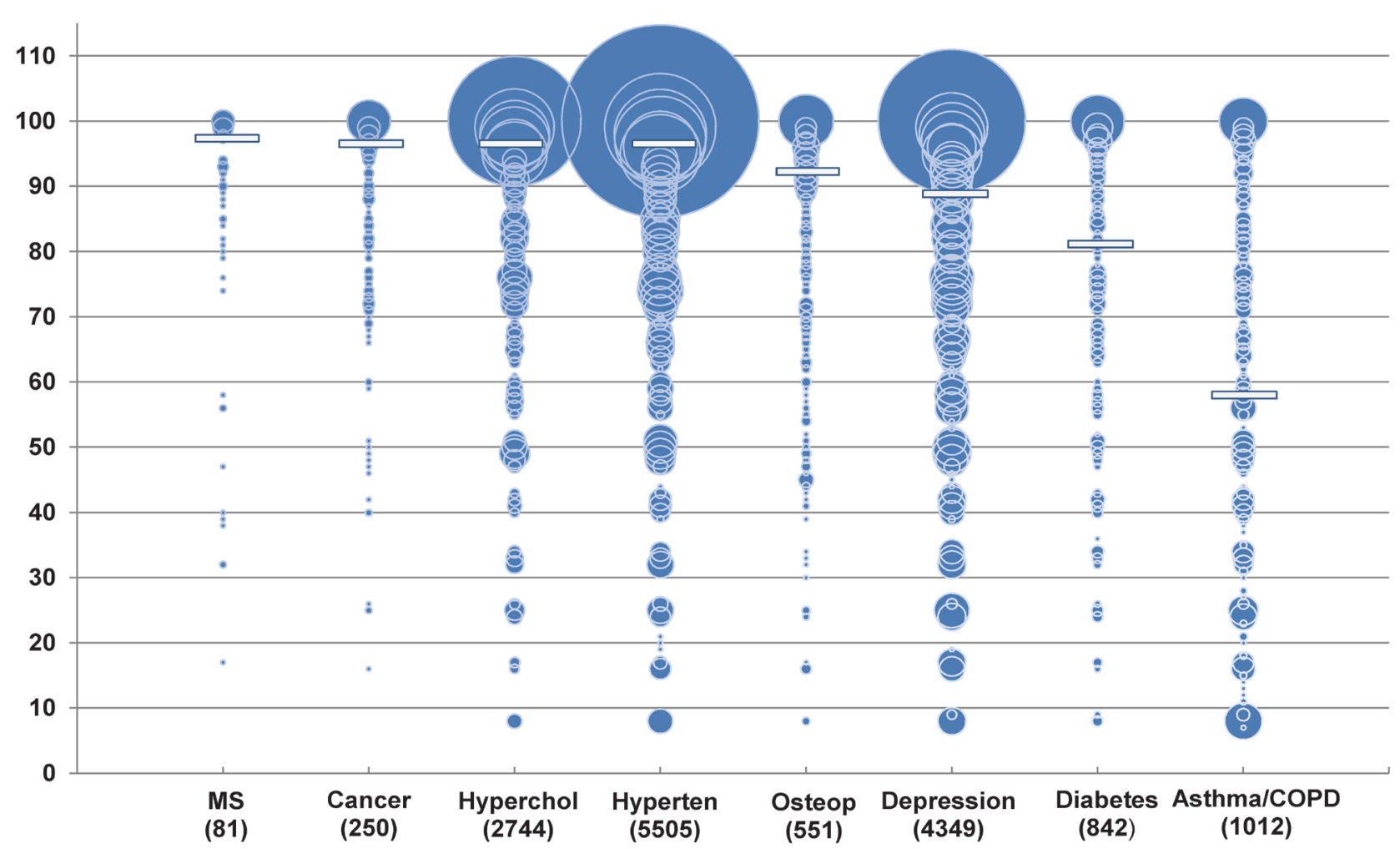

Figure 1. Distribution of medication possession ratios for eight conditions among 15334 patients with one condition and one medication (Bubble area is proportional to sample size. Median MPR indicated by horizontal bar.)

Overall, adherence rates were higher for those living in higher SES areas and for whites. Those in the lowest quartile of the living area variables (education, poverty, income) had lower drug adherence than those in other quartiles. When dividing age into quartiles, those in the lowest age quartile had the lowest adherence rates. Where differences by sex were found (hypertension, diabetes, and hyperlipidemia), men had higher adherence rates than women. For three of eight conditions (hypertension, depression, hyperlipidemia) increasing comorbidity was associated with lower adherence. Further, for six of eight conditions, adherence was higher in those with fewer conditions and on fewer drugs.

The patterns of associations from the logistic regression models (table 3) matched those of the bivariate results for gender, race, and age. However, in the regression models the census variable for high school education was not related to adherence. Adherence was also not related to median income among those with diabetes, or comorbidity or number of medications among those with asthma/COPD.

\section{Discussion}

The issue of adherence to medication is a growing concern. The World Health Organization identified it as adding to the burden of disease, ${ }^{11,26}$ and Carolyn M. Clancy, MD, director of the Agency for Healthcare Research and Quality has declared "Medication adherence is America's new drug problem." ${ }^{\prime 2}$ Further as the population ages and faces more chronic conditions, maintaining essential treatments is likely to be an increasing concern.
To address this issue, we conducted a study that examined adherence for eight conditions using patients with prescription coverage drawn from a large integrated health system. This allowed comparisons of adherence rates across conditions as well as an examination of patterns of correlates with adherence across conditions. What we found was relatively consistent with those who have reported on studies focusing on single conditions. First, as most others, we found that adherence was not optimal. ${ }^{1-7}$ We also found, as others have reported, lower adherence in minorities, those with lower SES, multiple conditions, taking multiple drugs, and multiple dosing. ${ }^{27,28}$ While five of the eight conditions studied found $75 \%$ of patients adherent (MPRs $>0.80$ ), higher than adherence rates reported by others, there remains room for improvement. ${ }^{12}$ In an examination of randomized controlled trials of interventions for enhancing adherence, Haynes and colleagues ${ }^{29}$ found that less than half of prescribed doses were taken by people prescribed self-administered medications. In another study by Rasmussen, ${ }^{30}$ focusing on lipid-lowering drugs, the rate of discontinuation was $38 \%$ after one year. In patients with hypertension, non-compliance to treatment ran between $15 \%$ to $54 \%{ }^{31}$ Others have cited rates between $18 \%$ to $80 \%{ }^{32,33}$ Lafata et $\mathrm{al}^{134}$ conducted a retrospective cohort study to measure adherence over a 24-month period among patients in a setting much like our own. Using pharmacy claims to estimate MPRs, they found $43 \%$ of patients not maintaining their regimens after 14 months. ${ }^{34}$ In another study examining drug therapies for osteoporosis, overall adherence was $52 \%{ }^{35}$ 
Table 2. Binary drug adherence (MPR $\geq 80 \%$ ) by patient characteristics, within condition ( $N=31636)$. Percentage with medication possession ratio $\geq 80 \%$ on ALL drugs.

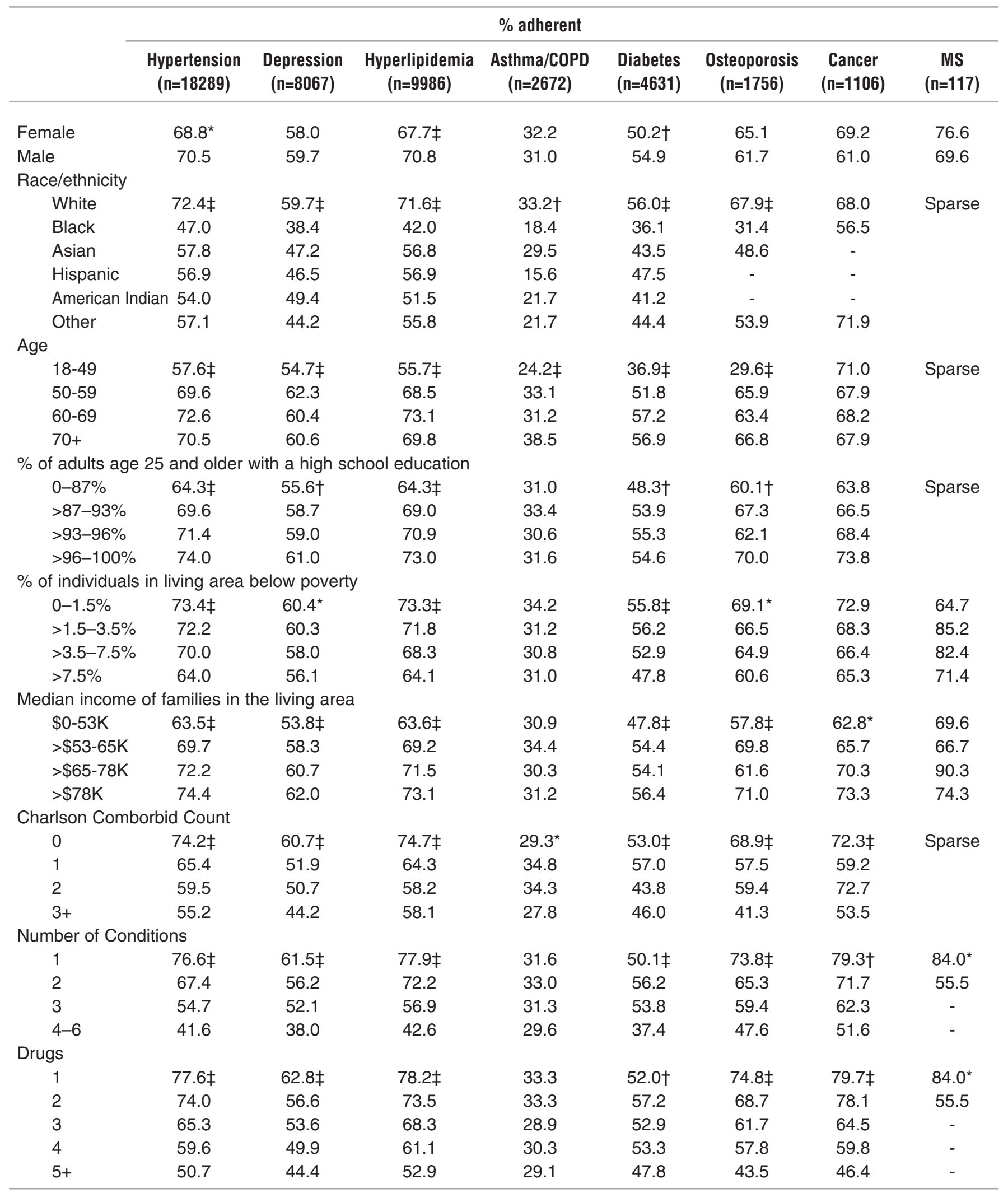

(Note: people can be in multiple columns if they have multiple conditions.)

${ }^{*} P<0.05 ; \dagger P<0.01 ; \ddagger P<0.001$ Pearson chi-square

$\mathrm{N}=20 /$ row min for reporting.

COPD, chronic obstructive pulmonary disease; MS, multiple sclerosis 
Table 3. Logistic regression analysis: predicting adherence to all drugs, within condition.

\begin{tabular}{|c|c|c|c|c|c|c|c|}
\hline & \multicolumn{7}{|c|}{$\%$ adherent } \\
\hline & $\begin{array}{l}\text { Hypertension } \\
(\mathrm{n}=17280)\end{array}$ & $\begin{array}{l}\text { Depression } \\
(\mathrm{n}=7550)\end{array}$ & $\begin{array}{l}\text { Hyperlipidemia } \\
(\mathrm{n}=9421)\end{array}$ & $\begin{array}{l}\text { Asthma/COPD } \\
\quad(\mathrm{n}=2481)\end{array}$ & $\begin{array}{l}\text { Diabetes } \\
(n=4283)\end{array}$ & $\begin{array}{l}\text { Osteoporosis } \\
(\mathrm{n}=1669)\end{array}$ & $\begin{array}{l}\text { Cancer } \\
(\mathrm{n}=1048)\end{array}$ \\
\hline Female vs male & $\begin{array}{c}0.89 \dagger \\
(0.84-0.96)\end{array}$ & $\begin{array}{c}0.90 \\
(0.81-1.00)\end{array}$ & $\begin{array}{c}0.84 \dagger \\
(0.77-0.93)\end{array}$ & $\begin{array}{c}1.02 \\
(0.85-1.22)\end{array}$ & $\begin{array}{c}0.82 \dagger \\
(0.72-0.93)\end{array}$ & $\begin{array}{c}1.06 \\
(0.68-1.66)\end{array}$ & $\begin{array}{c}1.23 \\
(0.82-1.85)\end{array}$ \\
\hline Race white vs nonwhite & $\begin{array}{c}2.16 \ddagger \\
(1.95-2.38)\end{array}$ & $\begin{array}{c}1.73 \ddagger \\
(1.45-2.06)\end{array}$ & $\begin{array}{c}2.03 \ddagger \\
(1.75-2.35)\end{array}$ & $\begin{array}{c}1.76 \ddagger \\
(1.29-2.40)\end{array}$ & $\begin{array}{c}1.66 \ddagger \\
(1.41-1.95)\end{array}$ & $\begin{array}{c}2.18 \ddagger \\
(1.57-3.03)\end{array}$ & $\begin{array}{c}0.71 \\
(0.37-1.38)\end{array}$ \\
\hline \multicolumn{8}{|l|}{ Age (years) } \\
\hline $50-59$ vs $18-49$ & $\begin{array}{c}1.67 \ddagger \\
(1.47-1.89)\end{array}$ & $\begin{array}{c}1.53 \ddagger \\
(1.36-1.72)\end{array}$ & $\begin{array}{c}1.79 \ddagger \\
(1.50-2.13)\end{array}$ & $\begin{array}{c}1.51 \dagger \\
(1.17-1.94)\end{array}$ & $\begin{array}{c}1.82 \ddagger \\
(1.49-2.24)\end{array}$ & $\begin{array}{c}4.12 \ddagger \\
(1.94-8.76)\end{array}$ & $\begin{array}{c}0.85 \\
(0.44-1.66)\end{array}$ \\
\hline $60-69$ vs $18-49$ & $\begin{array}{c}2.07 \ddagger \\
(1.82-2.35)\end{array}$ & $\begin{array}{c}1.64 \ddagger \\
(1.42-1.89)\end{array}$ & $\begin{array}{c}2.41 \ddagger \\
(2.03-2.86)\end{array}$ & $\begin{array}{c}1.53 \dagger \\
(1.17-2.00)\end{array}$ & $\begin{array}{c}2.47 \ddagger \\
(2.01-3.04)\end{array}$ & $\begin{array}{c}4.24 \ddagger \\
(2.05-8.77)\end{array}$ & $\begin{array}{c}1.15 \\
(0.60-2.21)\end{array}$ \\
\hline $70+$ vs $18-49$ & $\begin{array}{c}1.99 \ddagger \\
(1.77-2.24)\end{array}$ & $\begin{array}{c}1.93 \ddagger \\
(1.66-2.26)\end{array}$ & $\begin{array}{c}2.40 \ddagger \\
(2.03-2.84)\end{array}$ & $\begin{array}{c}2.30 \ddagger \\
(1.78-2.96)\end{array}$ & $\begin{array}{c}2.56 \ddagger \\
(2.10-3.13)\end{array}$ & $\begin{array}{c}6.53 \ddagger \\
(3.19-13.35)\end{array}$ & $\begin{array}{c}1.37 \\
(0.74-2.55)\end{array}$ \\
\hline $\begin{array}{l}\% \text { of adults in living area } \\
\text { age } 25 \text { and older with a } \\
\text { high school education }\end{array}$ & $\begin{array}{c}1.00 \\
(0.99-1.01)\end{array}$ & $\begin{array}{c}1.00 \\
(0.99-1.01)\end{array}$ & $\begin{array}{c}1.00 \\
(1.00-1.01)\end{array}$ & $\begin{array}{c}1.00 \\
(0.98-1.01)\end{array}$ & $\begin{array}{c}1.00 \\
(0.99-1.01)\end{array}$ & $\begin{array}{c}1.00 \\
(0.98-1.01)\end{array}$ & $\begin{array}{c}0.99 \\
(0.97-1.02)\end{array}$ \\
\hline $\begin{array}{l}\text { Median income of families } \\
\text { in the living area (10Ks) }\end{array}$ & $\begin{array}{c}1.04 \ddagger \\
(1.02-1.07)\end{array}$ & $\begin{array}{c}1.05 \dagger \\
(1.01-1.08)\end{array}$ & $\begin{array}{c}1.04^{*} \\
(1.01-1.07)\end{array}$ & $\begin{array}{c}0.99 \\
0.94-1.05)\end{array}$ & $\begin{array}{c}1.04 \\
(0.99-1.08)\end{array}$ & $\begin{array}{c}1.09^{\star} \\
(1.02-1.17)\end{array}$ & $\begin{array}{c}1.09 \\
0.99-1.20\end{array}$ \\
\hline Charlson Comorbid Count & $\begin{array}{c}0.85 \ddagger \\
(0.82-0.88)\end{array}$ & $\begin{array}{c}0.89 \ddagger \\
(0.84-0.95)\end{array}$ & $\begin{array}{c}0.85 \ddagger \\
(0.81-0.89)\end{array}$ & $\begin{array}{c}0.99 \\
(0.92-1.08)\end{array}$ & $\begin{array}{c}0.84 \ddagger \\
(0.79-0.89)\end{array}$ & $\begin{array}{c}0.88^{\star} \\
(0.78-0.98)\end{array}$ & $\begin{array}{l}0.90^{*} \\
0.83-0.99\end{array}$ \\
\hline Number of Drugs & $\begin{array}{c}0.77 \ddagger \\
(0.75-0.79)\end{array}$ & $\begin{array}{c}0.81 \ddagger \\
(0.78-0.84)\end{array}$ & $\begin{array}{c}0.80 \ddagger \\
(0.78-0.82)\end{array}$ & $\begin{array}{c}0.88 \ddagger \\
(0.83-0.94)\end{array}$ & $\begin{array}{c}0.91 \ddagger \\
(0.88-0.95)\end{array}$ & $\begin{array}{c}0.75 \ddagger \\
(0.70-0.81)\end{array}$ & $\begin{array}{l}0.71 \ddagger \\
0.65-0.77\end{array}$ \\
\hline C statistic & 0.66 & 0.61 & 0.66 & 0.60 & 0.63 & 0.68 & 0.66 \\
\hline \multicolumn{8}{|c|}{$\begin{array}{l}\text { Odds ratio and } 95 \% \mathrm{Cl} \text { for odds ratio reported in table } \\
{ }^{*} P<0.05 ; \dagger P<0.01 ; \ddagger P<0.001\end{array}$} \\
\hline COPD, chronic obstructive pul & nonary disease & & & & & & \\
\hline
\end{tabular}

A more recent study compared adherence and persistence across six chronic medication classes. ${ }^{11}$ The investigators found adherence decreased with increasing age. The authors recommended focusing quality improvement efforts where non-adherence was found to be most costly. ${ }^{11}$ While our focus was not on the same conditions or outcomes, we also believe it is essential to focus efforts on those conditions with the poorest adherence. In our integrated health system the conditions with the poorest adherence and biggest need for improvement were asthma (33\%) and diabetes (51\%). We also have clear evidence of patient characteristics shown to be associated with non-adherence. There are several potential areas to target for interventions from prescribing and nurse/patient education in the clinic to reminders from the pharmacy.

Minorities were consistently less adherent. This may be secondary to drug-related issues. Language barriers and cultural beliefs should be explored further to better understand their role in adherence. Generally, where differences were found by sex, it was most often men who were more adherent. It may be that women, who are frequently the primary caregivers, spend less time and energy taking care of themselves. Patient education surrounding the importance of continuing needed medication may be worthy in our female population. Similarly, taking extra time with those on multiple medications, where adherence was lower, to ensure patients understand the importance of not treating one condition at the detriment of another, is essential. We hypothesized that having readily available pharmacies in our medical clinics would result in better adherence than had been reported by others, but we found that this alone did not make the health system immune to non-adherence.

\section{Limitations and Strengths}

This study was conducted in a single health system, thus results may not be generalizable to all systems. However, the patterns of adherence were quite similar to what others have reported. Secondly, we assumed that obtaining a prescription was equivalent to actually taking the medication. Thus, we may be presenting a more optimistic assessment than what is actually true. There are multiple approaches to measuring medication adherence, and some might suggest that a different approach may be preferable. Hess, in comparing methods, found all provided similar values. ${ }^{18}$ Further, it was the method most used by others with databases similar to ours. While some have questioned the validity of using a cut-point of MPR of 80 , the cut-point is a common approach and served 
our purposes. ${ }^{18}$ Our intention was not to determine optimal clinical cut-points, rather, it was to assess which chronic conditions require the most immediate intervention efforts. Our study provided essential evidence that more work needs to be done to encourage patients to take their prescribed medications and allowed us to identify the two conditions most in need of attention.

Our decision to include all diabetes patients may be questioned by some. Researchers have included insulin-only users ${ }^{36,37}$ and excluded them. ${ }^{38}$ Some have used an adjusted MPR (multiplying by a factor of 1.5). ${ }^{39} \mathrm{We}$ examined the data in all manners for these individuals, and all results (51-60\% adherent), regardless of approach, indicated a need to boost adherence.

Another limitation was our use of contextual variables as a proxy for SES rather than using patient-level variables. We did not have direct access to such data and felt the proxy could provide needed insight. ${ }^{25}$

Our exclusion criteria of omitting those whose prescriptions were for less than 28 days excluded slightly over $7 \%$ of the prescriptions, but we did not want to include those that may have been prescribed short-term treatment. More importantly, we eliminated those who were on a given medication for less than one year from our analyses. We did this to ensure we did not categorize anyone whose initial therapy did not work for them as non-adherent. Our goal was to focus on adherence patterns in patients attempting to take medications chronically. Our analysis presented the best case scenario for our health plan and still evidenced conditions where intervention is sorely needed.

There was also concern about not obtaining full information on patients obtaining \$4 generic medications. Understanding the robustness of our pharmacy data has resulted in our pharmacy division monitoring what appears in our claims data and the level of potentially missing data. Through internal, unpublished analysis, we have determined the various incentives programs have had small impact on the fills data within our health plan.

Despite the limitations, we believe we were able to obtain comprehensive records on both diagnoses and pharmacy data on a large number of patients and carefully track drug usage across multiple conditions. The findings have provided direction to the health plan on conditions warranting special attention. Efforts are currently being focused on asthma and diabetes patients (where adherence was the lowest). Both providers and pharmacists have been encouraged to stress the importance of patients taking their medications as prescribed. Pill containers are being offered to serve as reminders and the pharmacy division is looking at alternative ways to package medications for those on many and complicated regimens. In addition, extra efforts are being made for minority patients, especially our immigrant populations, to be certain they understand the benefits of the medications being prescribed.

\section{Conclusion}

This study assessing medication adherence across eight diseases found variable adherence rates by condition and some conditions where rates were extremely low. In a population with prescription coverage offering multiple avenues with which to obtain medications, the findings pointed to the need to consider additional efforts to boost adherence rates. Further, the identification of patient characteristics associated with lower adherence has provided direction to begin to focus our efforts.

\section{References}

1. Cramer JA. A systematic review of adherence with medications for diabetes. Diabetes Care 2004;27:1218-1224.

2. Gold DT, Silverman S. Review of adherence to medications for the treatment of osteoporosis. Curr Osteoporos Rep 2006;4:21-27.

3. Krousel-Wood M, Thomas S, Muntner P, Morisky D. Medication adherence: a key factor in achieving blood pressure control and good clinical outcomes in hypertensive patients. Curr Opin Cardiol 2004;19:357-362.

4. LaRosa JH, LaRosa JC. Enhancing drug compliance in lipidlowering treatment. Arch Fam Med 2000;9:1169-1175.

5. Murray MD, Young JM, Morrow DG, Weiner M, Tu W, Hoke SC, Clark DO, Stroupe KT, Wu J, Deer MM, Bruner-England TE, Sowinski KM, Smith FE, Oldridge NB, Gradus-Pizlo I, Murray LL, Brater DC, Weinberger M. Methodology of an ongoing, randomized, controlled trial to improve drug use for elderly patients with chronic heart failure. Am J Geriatr Pharmacother 2004;2:53-65.

6. Osman LM. How do patients' views about medication affect their self-management in asthma? Patient Educ Couns 1997;32:S43-S49.

7. Schroeder K, Fahey T, Ebrahim S. How can we improve adherence to blood pressure-lowering medication in ambulatory care? Systematic review of randomized controlled trials. Arch Intern Med 2004;164:722-732.

8. Chan DC, Shrank WH, Cutler D, Jan S, Fischer MA, Liu J, Avorn J, solomon D, Brookhart MA, Chouldhry NK. Patient, physician, and payment predictors of statin adherence. Med Care 2010;48:196-202.

9. Shin DW, Park JH, Park EC, Kim SY, Kim SG, Choi JY. Antihypertensive medication adherence in cancer survivors and its affecting factors: results of a Korean population-based study. Support Care Cancer 2010;19:211-220.

10. Roebuck MC, Liberman JN, Gemmill-Toyama M, Brennan TA. Medication adherence leads to lower health care use and costs despite increased drug spending. Health Aff (Millwood) 2011;30:91-99.

11. Yeaw J, Benner JS, Walt JG, Sian S, Smith DB. Comparing adherence and persistence across 6 chronic medication classes. J Manag Care Pharm 2009; 15:728-740.

12. Ostrowski M. Report takes aim at America's other drug problem: Poor adherence. [editorial] J Fam Pract 2007;56:734.

13. Oh DL, Sarafian F, Silvestre A, Brown T, Jacobson L, badri S, Detels R. Evaluation of adherence and factors affecting adherence to combination antiretroviral therapy among White, Hispanic, and Black men in the MACS Cohort. J Acquir Immune Defic Syndr 2009;52:290-293.

14. Poon I, Lal LS, Ford ME, Braun UK. Racial/ethnic disparities in medication use among veterans with hypertension and dementia: a national cohort study. Ann Pharmacother 2009;43:185-193. 
15. Steiner JF, Ho PM, Beaty BL, Dickinson LM, Hanratty R, Zeng C, Tavel HM, Havranek EP, Davidson AJ, Magid DJ, Estacio RO. Sociodemographic and clinical characteristics are not clinically useful predictors of refill adherence in patients with hypertension. Circ Cardiovasc Qual Outcomes 2009;2:451-457.

16. Trinacty CM, Adams AS, Soumerai SB, Zhang F, Meigs JB, Piette JD, Ross-Degnan D. Racial differences in long-term adherence to oral antidiabetic drug therapy: a longitudinal cohort study. BMC Health Serv Res 2009;9:24.

17. Yang Y, Thumula V, Pace PF, Banahan BF 3rd, Wilkin NE, Lobb WB. Predictors of medication nonadherence among patients with diabetes in Medicare Part D programs: a retrospective cohort study. Clin Ther 2009;31:2178-2188; discussion 2150-2171.

18. Hess LM, Raebel MA, Conner DA, Malone DC. Measurement of adherence in pharmacy administrative databases: a proposal for standard definitions and preferred measures. Ann Pharmacother 2006;40:1280-1288.

19. Halpern R, Agarwal S, Dembek C, Borton L, Lopez-Bresnahan $\mathrm{M}$. Comparison of adherence and persistence among multiple sclerosis patients treated with disease-modifying therapies: a retrospective administrative claims analysis. Patient Prefer Adherence 2011;5:73-84.

20. Briesacher BA, Andrade SE, Fouayzi H, Chan KA. Medication adherence and use of generic drug therapies. Am J Manag Care 2009; 15:450-456.

21. Sedjo RL, Cox ER. Lowering copayments: impact of simvastatin patent expiration on patient adherence. Am J Manag Care 2008;14:813-818.

22. Peterson AM, Nau DP, Cramer JA, Benner J, Gwadry-Sridhar F, Nichol M. A checklist for medication compliance and persistence studies using retrospective databases. Value Health 2007;10:3-12.

23. International Society of Pharmacoeconomics and Outcomes Research. ISPOR Medication Compliance Special Interest Group (Med Comp). Draft-Appendix A. Medication compliance special interest group checklist for medication compliance studies using retrospective drug utilization data. Available at: http://www.ispor.org/sigs/eval_checklistdraft. asp. Accessed April 1, 2012.

24. Solomon DH, Iversen MD, Avorn J, Gleeson T, Brookhart MA, Patrick AR, Rekedal L, Shrank WH, Lii J, Losina E, Katz JN. Osteoporosis telephonic intervention to improve medication regimen adherence: a large, pragmatic, randomized controlled trial. Arch Intern Med 2012; 172:477-483.

25. Richards TB, Croner CM, Rushton G, Brown CK, Fowler L. Geographic information systems and public health: mapping the future. Public Health Rep 1999;114:359-373.

26. World Health Organization. Adherence to long-term therapies : evidence for action. Sabaté E, ed. Geneva: World Health Organization; 2003. Available at: http://www.who.int/chp/ knowledge/publications/adherence_introduction.pdf. Accessed April 1, 2012.

27. Claxton AJ, Cramer J, Pierce C. A systematic review of the associations between dose regimens and medication compliance. Clin Ther 2001;23:1296-1310.

28. Kalichman SC, Ramachandran B, Catz S. Adherence to combination antiretroviral therapies in HIV patients of low health literacy. J Gen Intern Med 1999;14:267-273.

29. Haynes RB, Ackloo E, Sahota N, McDonald HP, Yao X. Interventions for enhancing medication adherence. Cochrane Database Syst Rev. 2008(2):CD000011.

30. Rasmussen JN, Chong A, Alter DA. Relationship between adherence to evidence-based pharmacotherapy and long-term mortality after acute myocardial infarction. JAMA 2007;297:177-186.
31. Okken VS, Niemeijer MG, Dijkstra A, Baars MW, Said S, Hoogenberg K, ORfgen H, Otten S, Cleophas TJ. The effect of physical, social and psychological factors on drug compliance in patients with mild hypertension. Neth Heart J 2008;16:197-200.

32. Krueger KP, Berger BA, Felkey B. Medication adherence and persistence: a comprehensive review. Adv Ther 2005; 22:313-356

33. Goff SL, Mazor KM, Meterko V, Dodd K, Sabin J. Patients' beliefs and preferences regarding doctors' medication recommendations. J Gen Intern Med 2008;23:236-241.

34. Lafata JE, Cerghet M, Dobie E, Schultz L, Tunceli K, Reuther J, Elias S. Measuring adherence and persistence to diseasemodifying agents among patients with relapsing remitting multiple sclerosis. J Am Pharm Assoc (2003) 2008; 48:752-757.

35. Kothawala P, Badamgarav E, Ryu S, Miller RM, Halbert RJ. Systematic review and meta-analysis of real-world adherence to drug therapy for osteoporosis. Mayo Clin Proc 2007;82:1493-1501.

36. Egede LE, Gebregziabher M, Hunt KJ, Axon RN, Echols C, Gilbert GE, Mauldin PD. Regional, geographic, and ethnic differences in medication adherence among adults with type 2 diabetes (February). Ann Pharmacother. 2011 Feb 8. [Epub ahead of print]

37. Chang A, Liberman J, Coulen C, Berger J, Brennan T. Valuebased insurance design and antidiabetic medication adherence. Am J Pharm Benefits 2010;2:39-44.

38. Lau DT, Nau DP. Oral antihyperglycemic medication nonadherence and subsequent hospitalization among individuals with type 2 diabetes. Diabetes Care 2004;27:2149-2153.

39. Kleinman NL, Schaneman JL, Lynch WD. The association of insulin medication possession ratio, use of insulin glargine, and health benefit costs in employees and spouses with type 2 diabetes. J Occup Environ Med 2008;50:1386-1393.

\section{Author Affiliations}

Sharon J Rolnick, PhD, MPH*; Pamala A. Pawloski, PharmD*; Brita D. Hedblom, BS*; Stephen E. Asche, MA*; and Richard J. Bruzek, PharmD"

"HealthPartners Research Foundation, Minneapolis, MN

rHealthPartners, Pharmacy Services Minneapolis, MN 
Appendix A. Oral Prescription Medications.

Disease Medication Category

Antihyperlipidemic Agents

Asthma/COPD

Depression

Natural HMG CoA reductase inhibitors

Niacin

HMG CoA reductase inhibitor combination

HMG CoA reductase inhibitors

Bile acid sequestrants

Fibric acid derivatives

Antihyperlipidemics - misc

Intestinal cholesterol absorption inhibitors

Intest cholest absorp inhib- HMG CoA reductase inhib comb

Nicotinic acid derivatives

Beta adrenergics

Adrenergic combinations

Xanthines

Bronchodilators - anticholinergics

Nasal antihistamines

Steroid inhalants

Nasal steroids

Steroid combinations

Glucocorticosteroids

Anti-inflammatory agents

Nasal mast cell stabilizers

Mineralocorticoids

Mixed adrenergics

Nasal anticholinergics

Leukotriene receptor antagonists

5-lipoxygenase inhibitors

Trazodone HCL-dietary management product

Tricyclic antidepressants

Combination psychotherapeutics

Antidepressants - misc.

Antianxiety agents - misc.

Benzodiazepines \& tricyclic agents

Selective serotonin reuptake inhibitors (SSRIs)

Serotonin-norepinephrine reuptake inhibitors (SNRIs)

Premenstrual dysphoric disorder (PMDD) agents - SSRIs

Modified cyclics

Thienbenzodiazepines \& SSRIs

Phenothiazines \& tricyclic agents

Diabetes

Alpha-glucosidase inhibitors

Sulfonylureas

Incretin mimetic agents (GLP-1 receptor agonists)

Sulfonylurea-biguanide combinations 
Biguanides

Antidiabetic D-phenylalanine derivatives

Thiazolidinediones

Sulfonylurea-thiazolidinedione combinations

Thiazolidinedione-biguanide combinations

Meglitinide analogues

Dipeptidyl peptidase-4 (DPP-4) inhibitors

Dipeptidyl peptidase-4 (DPP-4) inhibitor-biguanide combinations

Hypertension

Beta blockers cardio-selective

Alpha 1-adrenoceptor antagonists

Direct renin inhibitors

Direct renin inhibitors \& thiazide/thiazide-like combinations

Reserpine

Diuretic combinations

Potassium sparing diuretics

Calcium channel blockers

Ace inhibitor \& calcium channel blocker combinations

Angiotensin II receptor antag \& CA channel blocker comb

Beta blocker \& diuretic combinations

Ace inhibitors \& thiazide/thiazide-like combinations

Ace inhibitors

Thiazides and thiazide-like diuretics

Loop diuretics

Angiotensin II receptor antagonists

Angiotensin II receptor antagonists \& thiazide combinations

Beta blockers non-selective

Alpha-beta blockers

Adrenolytics-central \& thiazide combinations

Antiadrenergics - centrally acting

Antiadrenergics - peripherally acting

Selective aldosterone receptor antagonists (SARAs)

Vasodilators \& thiazide combinations

Vasodilators

Nitrate \& vasodilator combinations

Agents for pheochromocytoma

Multiple Sclerosis

Multiple sclerosis agents

Multiple sclerosis agents - interferons

Multiple sclerosis agents - monoclonal antibodies

Oncology Agents

Bisphosphonates

Alkylating agents

Aromatase inhibitors

Antiandrogens

Antineoplastic - multikinase inhibitors

Nitrogen mustards

Androgens

Antineoplastic - tyrosine kinase inhibitors 
Estrogens-antineoplastic

LHRH analogs

Progestins

Immunomodulators for myelodysplastic syndromes

Selective estrogen receptor modulators (SERMs)

Antiestrogens

Imidazotetrazines

Antileprotics

Retinoids

Osteoporosis

Calcium combinations

Calcium

Vitamin D

Antacids - calcium salts

Parathyroid hormone and derivatives

Bisphosphonates

Calcitonins 